\title{
Estandarización y evaluación de ELISA en eluidos de sangre seca recolectada en papel de filtro para el diagnóstico de cisticercocis
}

\author{
Augusto Corredor ${ }^{1}$, Myriam C. López², Sofía Duque², Rubén S. Nicholls ${ }^{3}$
}

\begin{abstract}
Resumen
Se estandarizó y evaluó la prueba inmunoenzimática ELISA para la detección de anticuerpos contra larva de Taenia solium usando eluidos de sangre seca obtenida por punción digital y recolectada en papel de filtro. La dilución óptima de muestra fue de 1:400, la cual es equivalente a la obtenida a partir de suero. EI ELISA mostró una sensibilidad de $100 \%$ y una especificidad de $97,6 \%$, lo cual permite su utilización tanto para diagnóstico como para encuestas seroepidemiológicas.
\end{abstract}

\section{Summary}

An enzyme-linked immunosorbent assay (ELISA) to detect Taenia solium larvae antibodies was standardized and evaluated. The ELISA test was performed on eluates of dried blood collected on filter paper, the eluates having been obtained by digital puncture. Optimum sample dilution was 1:400 which is equivalent to that obtained from serum samples. The sensitivity and specificity of this ELISA test were $100 \%$ and $97.6 \%$, respectively. These results suggest its use as a tool both for diagnostic purposes and epidemiological surveys.

La prueba de ELISA para la detección de anticuerpos contra larva de Taenia solium en muestras de suero demostró una sensibilidad de $100 \%$ y una especificidad de $97,6 \%$ (1), siendo una prueba de gran ayuda para el diagnóstico clínico. Sin embargo, cuando se hacen estudios seroepidemiológicos, para los cuales hay necesidad de recolectar un número grande de muestras, la obtención de sangre por punción venosa y su transporte se hacen difíciles.

Los eluidos de sangre seca recolectada sobre papel de filtro han sido utilizados anteriormente para el diagnóstico de enfermedades parasitarias tales como la esquistosomiasis y la tripanosomiasis americana $(2,3)$. Por esto y por las dificultades anteriormente mencionadas, el presente trabajo tuvo por objeto estandarizar y evaluar la prueba de ELISA para el diagnóstico de la cisticercosis empleando eluidos de sangre obtenida por punción digital en papel de filtro.

\section{Materiales y métodos}

\section{Muestras}

Se recolectaron 52 muestras de sangre, tanto en papel de filtro como en tubo seco, para

1 Instituto de Salud en el Trópico, Facultad de Medicina, Universidad Nacional de Colombia, Santa Fe de Bogotá, D.C., Colombia.

2 Laboratorio de Parasitología, Instituto Nacional de Salud, Santa Fe de Bogotá, D.C., Colombia.

3 Laboratorio de Parasitología, Instituto Nacional de Salud; Departamento de Microbiología y Parasitología, Facultad de Medicina, Universidad Nacional de Colombia, Santa Fe de Bogotá, D.C., Colombia. 
obtener suero. De éstas, seis eran de pacientes con cisticercosis diagnosticada por tomografía computadorizada (TC) cerebral, cuatro de pacientes con neurocisticercosis cuyo diagnóstico se confirmó por visualización directa del parásito, 40 de individuos sanos y dos de pacientes con otras helmintiasis que pudiesen dar reacción cruzada.

\section{Recolección de las muestras sobre papel de filtro}

Se recolectaron muestras de sangre en papel de filtro Whatman \# 3, delimitando previamente un área circular con capacidad de absorción de $60 \mu \mathrm{L}$ de sangre. Las muestras se dejaron secar a temperatura ambiente sin exposición directa a la luz solar y, finalmente, se almacenaron a $4^{\circ} \mathrm{C}$.

\section{Procesamiento}

Para la obtención de suero, se recortó el círculo y se diluyó en $3 \mathrm{~mL}$ de solución tampponada (PBS) durante 24 horas, con lo cual se obtuvo una primera dilución equivalente a 1:100 de suero. A partir de ésta, se realizaron nuevas diluciones equivalentes a 1:200, 1:400, 1:800, $1: 1.600,1: 3.200$ y $1: 6.400$ con la finalidad de determinar la dilución óptima de la muestra para ser utilizada en la prueba.

\section{ELISA}

La prueba inmunoenzimática se realizó usando el método descrito previamente por López y colaboradores (1).

\section{Tratamiento estadistico}

La sensibilidad (S), especificidad (E), valor predictivo positivo (VPP) y valor predictivo negativo (VPN) de la prueba inmunoenzimática se determinaron utilizando una tabla de contingencia de $2 \times 2$ (4).

La determinación de la densidd óptica (DO) crítica se llevó a cabo comparando los valores promedios de las muestras positivas y negativas y estableciendo límites de confianza del $95 \%$.

\section{Resultados}

La dilución óptima de antígeno de larva de $T$. solium para llevar a cabo la prueba de ELISA fue de $20 \mu \mathrm{g} / \mathrm{mL}$ (figura 1).
La dilución óptima de suero obtenido de papel de filtro para realizar la prueba inmunoenzimática fue de 1:400 (figura 2).

La dilución óptima de conjugado anti-lgG humana (Sigma A5403) fue de 1:1.500 (figura 3).

La densidad óptica, definida como aquélla donde se observó una clara diferencia entre las muestras positivas y negativas, fue de 0,4 .

La sensibilidad y especificidad de la prueba fueron de $100 \%$ y $97,6 \%$, respectivamente, en pacientes parasitológicamente comprobados (cuadro 1) y de $83,3 \%$ de sensibilidad y $97,6 \%$

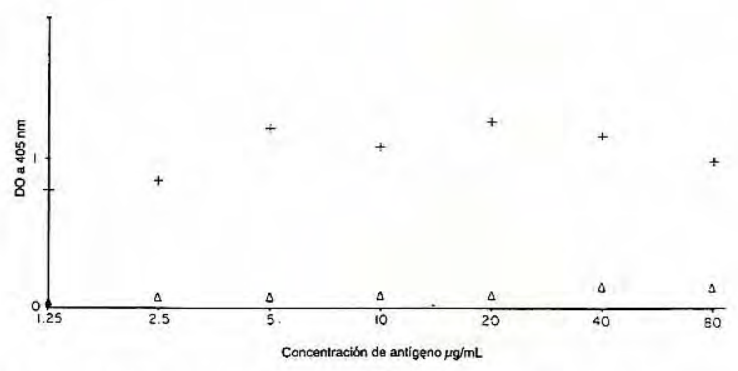

Figura 1. Dilución óptima de antígeno de $T$. solium.

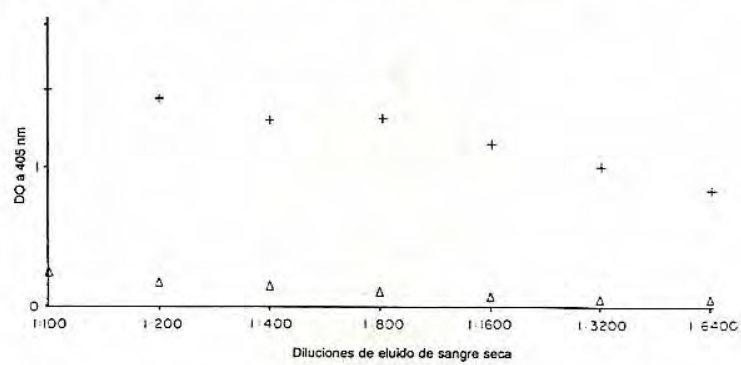

Figura 2. Dilución óptima de los eluidos de sangre.

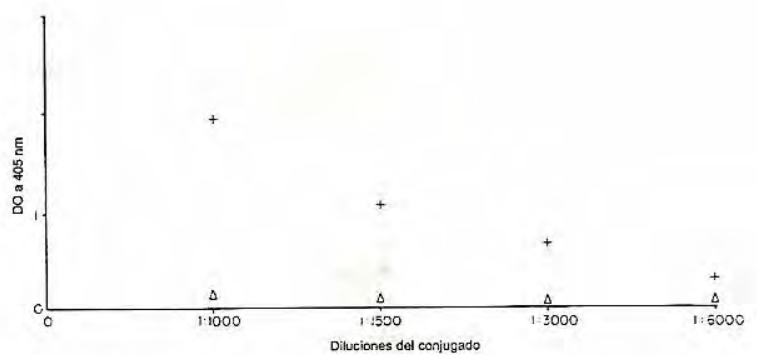

Figura 3. Dilución óptima del conjugado. 
de especificidad en pacientes diagnosticados por tomografía computadorizada (cuadro 2). Los valores predictivos positivo y negativo fueron de $80 \%$ y $100 \%$, respectivamente, en pacientes parasitológicamente comprobados (cuadro 1) y en pacientes diagnosticados por TC; los valores predictivos positivo y negativo fueron de $83,3 \%$ y $97,6 \%$, respectivamente (cuadro 2 ).

Cuadro 1. ELISA para el diagnóstico de neurocisticercosis en pacientes con diagnóstico parasitológico.

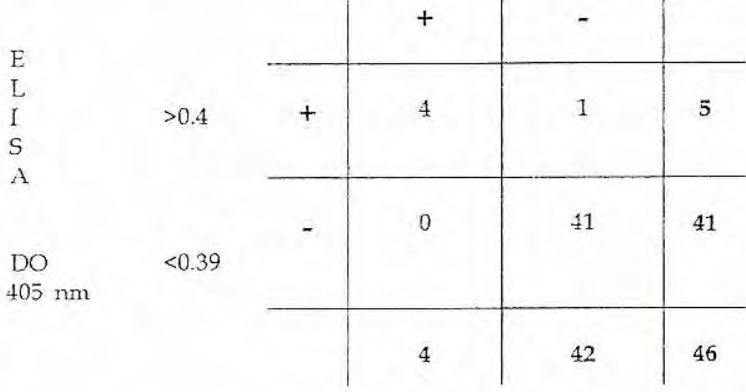

S:100\% E:97,6\% VPP:80\% VPN:100\%

Cuadro 2. ELISA para el diagnóstico de neurocisticercosis en pacientes con diagnóstico establecido por TC.

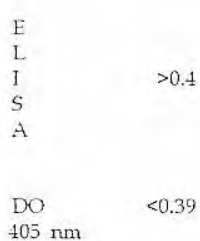

$$
405 \mathrm{rm}
$$$$
<0.39
$$

S:83,3\% E:97,6\% VPP:83,3\% VPN:97,6\%

\section{Discusión}

La dilución óptima de suero obtenida a partir de las muestras tomadas en papel de filtro y el valor de absorbancia son equivalentes a los utilizados en la prueba de ELISA para la detección de anticuerpos en muestras de suero (1).

Cuando se valora la prueba de ELISA para el diagnóstico de la cisticercosis con eluidos de sangre a partir de las muestras tomadas en papel de filtro, la sensibilidad de la prueba es de $100 \%$ en pacientes con diagnóstico parasitológico confirmado comparada con $83,3 \%$ en pacientes cuyo diagnóstico se estableció por TC. En estas mismas condiciones, la especificidad de la prueba es de $97,6 \%$ tanto en pacientes comprobados parasitológicamente como en pacientes diagnosticados por TC. Estos valores y la facilidad para la toma, transporte y almacenamiento de las muestras, permiten su utilización tanto para fines diagnósticos como para estudios seroepidemiológicos en los cuales se busca estimar la prevalencia de la infección determinando la presencia de anticuerpos contra la lanva de $T$. solium en la población general.

\section{Referencias}

1. López MC, Murillo C, Sarria N, Nicholls RS, Corredor A. Estandarización y evaluación de la prueba de ELISA para la detección de anticuerpos en LCR y suero en neurocisticercosis. Acta Neurol Col 1988;4:164-9.

2. Anderson RI, Sadun EH, Willians JS. A technique for the use of minute amounts of dried blood in fluorescent antibody tests for schistosomiasis. Exp Parasitol 1961;11:111-6.

3. Souza SL, de Camargo ME. The use of filter paper blood smears in practical fluorescent test for American trypanososmiasis serodiagnosis. Rev Inst Med Trop Sao Paulo 1966;8:259-66.

4. Griner PF, Mayewski RJ, Mushlin Al, Greenland P. Selection and interpretation of diagnostic tests and procedures. Ann Intern Med 1981;94:559-63. 